\title{
Surveillance report
}

\section{Pneumococcal Conjugate, Meningococcal C And Varicella Vaccination IN ITALY}

\author{
F D'Ancona, V Alfonsi, M Caporali, A Ranghiasci, ML Ciofi degli Atti, on behalf of the Regional referents for infectious \\ diseases and vaccinations*
}

National Centre for Epidemiology Surveillance and Health Promotion, Istituto Superiore di Sanità, Rome, Italy

\begin{abstract}
The 7-valent anti-pneumococcal conjugate vaccine (PCV), antimeningococcal $\mathrm{C}$-conjugate vaccine $(\mathrm{MenC})$ and varicella vaccine have been recently introduced in EU. In Italy, these vaccines have so far been recommended for use in specific groups. Since the health system is decentralised, the Regional Health Authorities (RHAs) can decide to recommend vaccination for other target populations. We conducted a survey to describe the recommendations on these vaccines currently in place in the 21 Italian regions. In November 2005, a standardised questionnaire was sent to RHAs, including information on the existence of regional recommendations, vaccination target population, and whether vaccines were provided free of charge, or at a reduced cost compared to pharmacies. Information reported in the questionnaires were followed up in May 2006. All 21 regions completed and returned the questionnaire and were contacted for follow-up. Recommendations about at least one of the three vaccines were present in 20 out of 21 regions. All included free of charge PCV offering to specific groups, while MenC and varicella immunisations were recommended in 17 and 19 regions, respectively. Recommendations for other individuals varied greatly by area: free of charge PCV and MenC vaccinations targeting all infants have been recommended in nine regions, and varicella vaccination targeting children in the second year of life in three regions. These different recommendations can lead to marked variation in vaccination coverage rates observed through the country, with a consequent different level of disease control. It is thus crucial to properly monitor vaccination coverage rates for $\mathrm{PCV}$, MenC and varicella, as these are not routinely collected at the national level.
\end{abstract}

\section{Introduction}

In Italy, childhood vaccinations are usually administered by vaccination clinics in Local Health Units, which are coordinated by the Health Authorities of the 21 Italian regions (Regional Health Authorities, RHAs). Since 2001, when the National Health System was decentralised, vaccination strategies to be implemented throughout the whole country should be agreed on by the Ministry of Health and the RHAs. Commissione Nazionale Vaccini (The National Committee on Vaccinations), where representatives of the RHAs, Ministry of Health, National Institute of Health (Istituto Superiore di Sanità, ISS), and scientific societies took part, proposes the national vaccination schedule and the national vaccination plan, which are submitted for approval to a political body, Conferenza Stato-Regioni (Government-Regions Committee). The current national schedule calls for universal vaccination against nine diseases: diphtheria, tetanus, pertussis, poliomyelitis, hepatitis $\mathrm{B}$, Haemophilus influenzae b, measles, mumps and pertussis. To guarantee the adherence of all 21 Italian regions to this schedule, and the availability of these vaccinations for all children, irrespective of their socioeconomic status, these nine vaccines are included in the list of essential health services that all regions must offer free of charge.

Other vaccines which have been authorised for marketing are available at full price in pharmacies, and RHAs can decide to offer them in Local Health Units, free of charge or at a reduced cost compared to the pharmacy price.

Vaccines for prevention of pneumococcal invasive diseases, meningococcal $C$ diseases and varicella recently became available on the European market, initiating a debate concerning their introduction into routine immunisation programs [1-3]. Pneumococcal and meningococcal $\mathrm{C}$ infections are characterised by a low transmissibility, with a basic reproduction rate lower than 2 [4,5], yet they can cause severe illnesses, ranging from pneumonia to meningitis and fulminant sepsis. In Europe, the estimated annual incidence per 100,000 population ranges from 0.3 to 20.3 for invasive pneumococcal disease and from 0.39 to 7.41 for meningococcal disease [6,7]. Incidence also varies by age groups, with highest figures observed in children $<2$ years of age $[8,9]$.

Varicella, on the other hand, is highly infectious, with a lifetime incidence of nearly $100 \%$. In temperate climates and in the absence of vaccination, $80 \%-98 \%$ of individuals acquire the infection by 15 years of age $[10,11]$. Though the disease is usually mild, the risk of complications is higher for children $<1$ year of age and people aged over 15 years (the risk increases with age) [12].

In Europe, nine countries have so far introduced the 7-valent anti-pneumococcal conjugate vaccine (PCV) in their routine immunisation programs [13], and six have introduced antimeningococcal $\mathrm{C}$-conjugate vaccine (MenC) [7]. Universal varicella vaccination has been introduced in one only country [14].

Universal immunisation has not yet been recommended in Italy for any of these vaccines. In fact, the current national vaccination plan recommends PCV, MenC and varicella vaccination for specific groups of population [15], which are summarised in the table. Since RHAs can choose to offer these vaccines to other target populations, we conducted a survey to describe the current recommendations on giving PCV, MenC and varicella vaccines in the 21 Italian regions.

\section{Methods}

In November 2005, we mailed to the 21 RHAs a questionnaire on $\mathrm{PCV}, \mathrm{MenC}$ and varicella vaccination strategies. The questionnaire included items on the existence of regional recommendations on these vaccinations, and their date of approval. If recommendations 


\section{T A B L E}

Target population for $\mathrm{PCV}, \mathrm{MEN}-\mathrm{C}$ and varicella vaccination, Italian national vaccination plan, 2005-2007

\begin{tabular}{|c|c|}
\hline PCV & $\begin{array}{l}\text { Children < } 5 \text { years of age presenting with: } \\
\text { - splenic dysfunction } \\
\text { immunodeficiency } \\
\text { - HIV infection } \\
\text { - chronic pulmonary diseases } \\
\text { : chronic cardiovascular diseases } \\
\text { - chronic river disorders } \\
\text { - diabetes mellitus } \\
\text { - cerebrospinal fluid leakage } \\
\text { - cochlear implant }\end{array}$ \\
\hline MEN C & $\begin{array}{l}\text { Individuals who present with: } \\
\text { - splenic dysfunction } \\
\text { - immunodeficiency }\end{array}$ \\
\hline Varicella & $\begin{array}{l}\text { Susceptible individuals who present one of the following } \\
\text { conditions: } \\
\text { - household of individuals with immunodeficiency } \\
\text { - acute lymphatic leukaemia in complete remission } \\
\text { - chronic renal failure } \\
\text { - } \text { HIV infections, with } \operatorname{CD} 4 \geq 25 \% \\
\text { - health workild-bearing age } \\
\text { - school workers }\end{array}$ \\
\hline
\end{tabular}

were in place, RHAs were asked to describe the vaccination target population, and whether vaccination of various target groups was performed free of charge, or at a reduced cost.

For PCV, the target population was divided into the following three subgroups, which are listed in National Vaccine Plan in order of priority:

a) specific groups, as listed in the table

b) children $<3$ years of age attending day-care facilities;

c) all infants in the first year of life.

For MenC, the following sub-groups were listed:

a) specific groups, as listed in the table;

b) all infants in the first year of life.

For varicella vaccine, the target population was also divided according to the priority order given in the National Plan, that is:

a) specific groups [Table],

b) adolescents with no clinical history of varicella;

c) all children in the second year of life.

For each target group, the RHA was asked whether the vaccine was administered free of charge, or at a reduced price compared to pharmacies.

In May 2006, we contacted all RHAs by telephone in order to verify the information provided in the returned questionnaires, and to update the responses if further recommendations had been issued since the questionnaire had been returned. All data were analysed at the Istituto Superiore Sanità, using Excel software.

\section{Results}

All 21 regions completed and returned the questionnaire and were contacted for follow-up.

Recommendations about the offering of at least one of these three vaccines existed in 20 out of 21 regions. Ten of these regions had approved their recommendations prior to the publication of the 2005-2007 National Vaccine Plan, while seven had approved or updated them in the period November 2005-May 2006.

\section{F I G U R E 1}

Italian regions recommending free of charge $\mathrm{PCV}$ by target population, as of May 2006

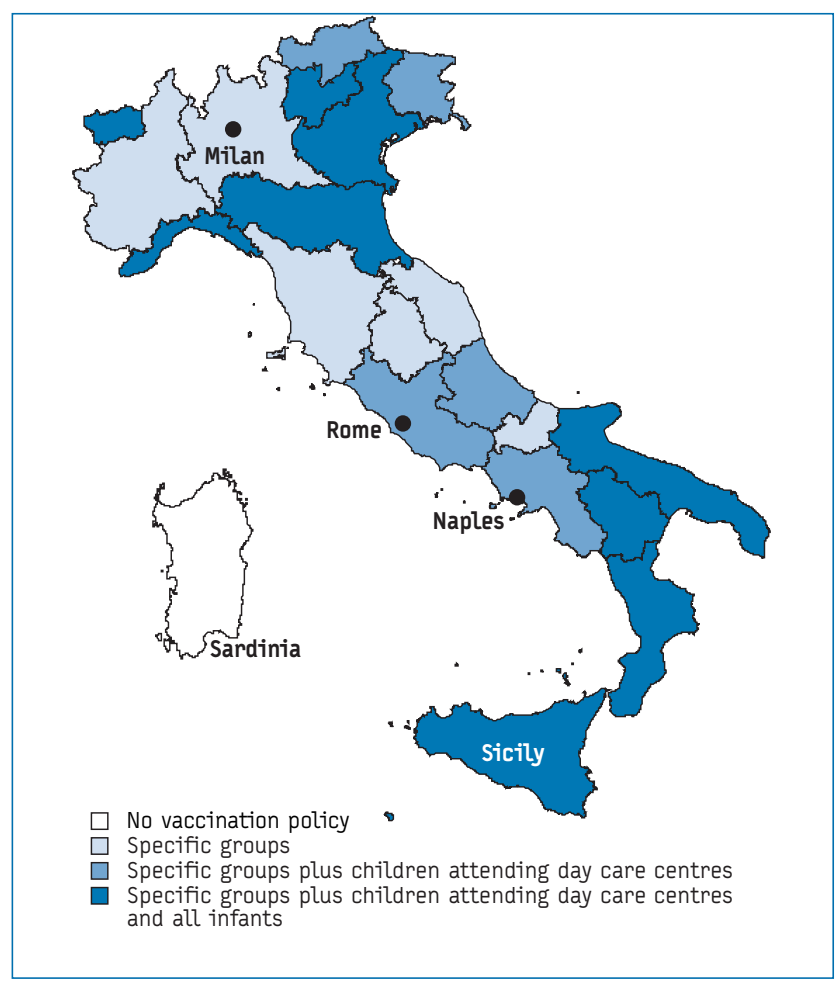

F I G U R E 2

Italian regions recommending free of charge MEN-C by target population, as of May 2006

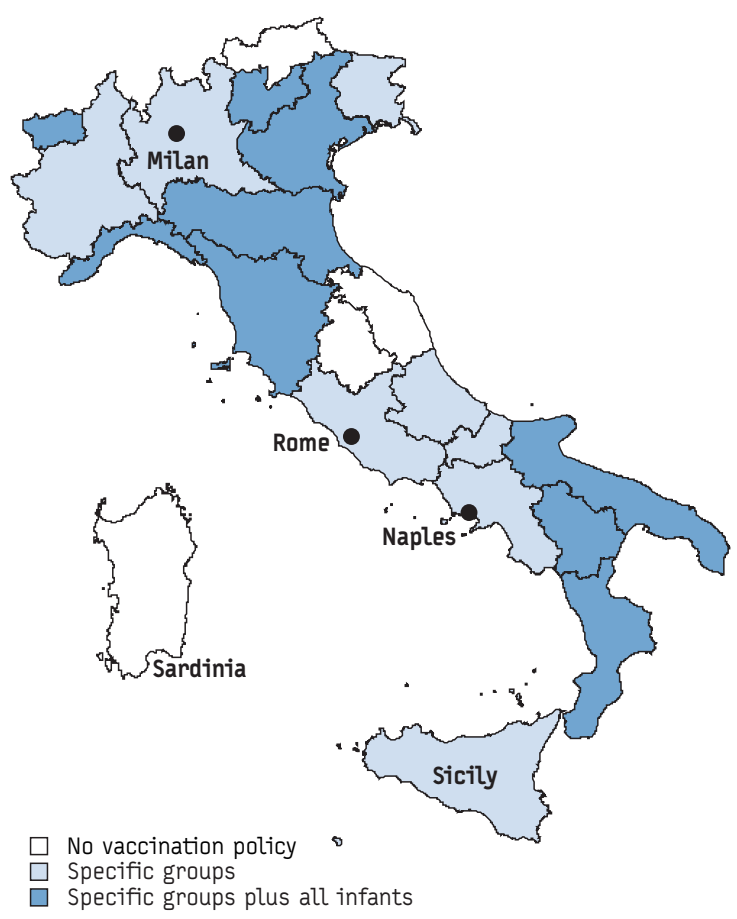


F I G U R E 3

Italian regions recommending free of charge varicella vaccine by target population, as of May 2006

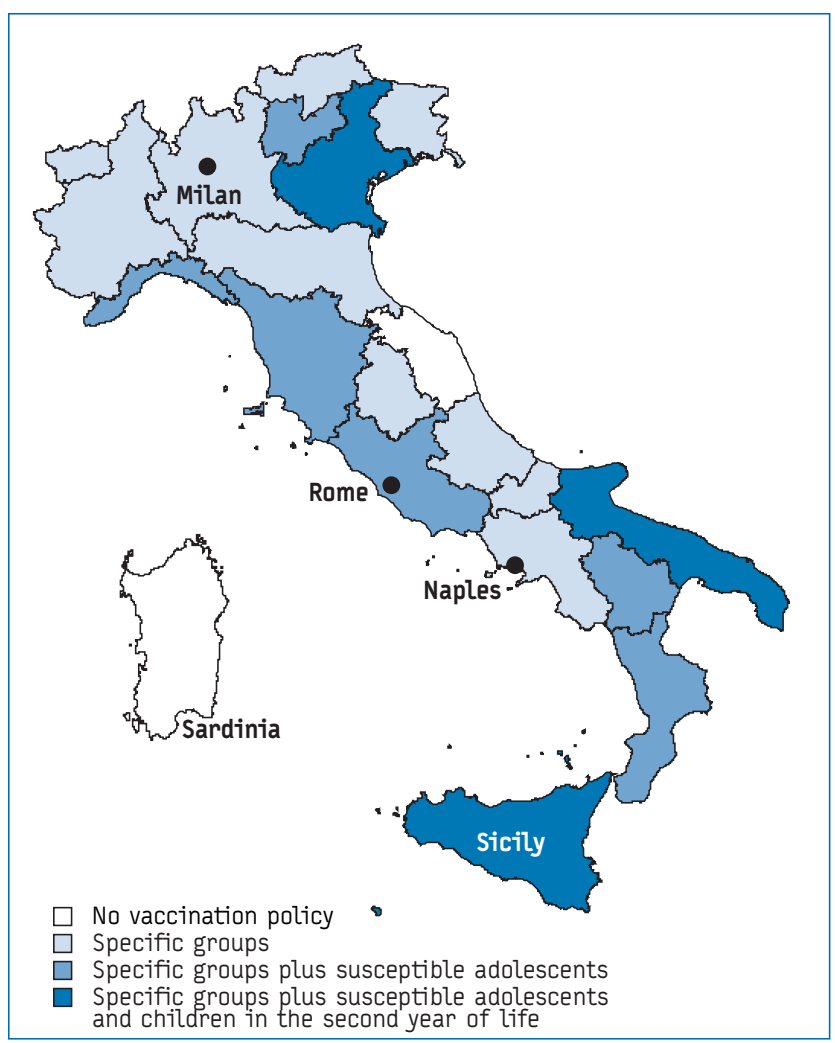

All 20 regional recommendations included PCV, while MenC and varicella vaccinations were considered in 17 and 19 regions, respectively. In all these regions, it was recommended that vaccination of specific population groups be given free of charge [Figures 1-3], while vaccination of other individuals varied greatly, as reported below.

\section{PCV vaccination}

Fourteen of the 20 regions provided PCV free of charge to children $<3$ years of age attending day-care facilities, and nine regions provided PCV free of charge to all infants [Figure 1]. In addition, eight regions made PCV available for infants at a reduced price.

\section{MEN C vaccination}

Of the 17 regions with MenC recommendations, nine included vaccination free of charge for all infants [Figure 2]. Vaccine at a reduced cost was available for infants in six additional regions.

\section{Varicella vaccination}

Vaccination free of charge for susceptible adolescents was recommended in nine out of 19 regions [Figure 3]; three of these nine regions also provided vaccine free of charge to children in the second year of life. Varicella vaccine at a reduced cost was available for susceptible adolescents in five of the remaining regions, and for children in the second year of life in four.

\section{Discussion}

The harmonisation of vaccination policies in countries with decentralised health systems presents a never-ending challenge, and this survey evaluated the regional adherence to national recommendations on three vaccines recently introduced onto the market. The Italian National Vaccination Plan identifies as priority target groups for PCV, MenC and varicella vaccination individuals with at high risk of acquiring the disease or who are more likely to develop complications [15]. The results of our survey show that the regional adherence to this recommendation is still not complete, and varies by type of vaccine, being highest for PCV (implemented in 20/21 regions), followed by varicella vaccine (19 regions), and MenC (17 regions). Efforts are therefore needed in order to guarantee proper protection of high risk population.

Universal PCV, MenC, and varicella vaccinations have not yet been introduced in Italy. For the first two vaccines, this was mainly due to the available data (although limited) showing a modest incidence of pneumococcal and meningococcal invasive diseases. In fact, in the years 2003-2005, an annual mean of 23 cases of pneumococcal meningitis was reported for children under 2 years of age, accounting for an annual incidence of 2.1-5.7 per 100,000 population $[16,17]$. When pneumococcal sepsis is also taken into account, annual incidence in children $<2$ years of age increases to $5.9-11.3$ per 100,000 population [17], which is lower than the weighted mean incidence of invasive pneumococcal diseases reported for western Europe (27.03 per 100,000 population) [18]. Italy has the lowest reported incidence of invasive meningococcal disease in Europe [7]. For meningococcal meningitis in particular, in the period 2003-2005, an annual mean of 50 cases was reported among children $<2$ years of age (incidence of 4.6 per 100,000 population), and of these cases, a mean of 18 (54.7\% of the serotyped isolates) were caused by serotype $C$ (incidence of 1.6 per 100,000 population) and could thus have been prevented by vaccination [16].

Varicella vaccination has not been introduced nationally because of the potential risk of suboptimal vaccination coverage. In fact, modelling studies have shown that coverage rates lower than $80 \%$ in the second year of life could increase the inter-epidemic interval, with an increase in the number of individuals acquiring the infection at older ages, when the risk of complications is higher $[19 ; 20]$. It was thus stated that universal vaccination should be introduced if vaccination coverage $>85 \%$ could be achieved and maintained [15].

The measure of reducing out-of-pocket vaccination costs is strongly recommended if vaccine acceptance is to be improved [21]. Results of this survey show that free of charge PCV and MenC vaccinations targeting all infants have been recommended in nine regions, and varicella vaccination targeting all children in the second year of life in three. As has previously been found for other vaccinations, such as mumps, measles and rubella (MMR) [22], we are now observing heterogeneous regional immunisation strategies. This can lead to marked variation in vaccination coverage rates observed through the country, with a consequent different level of control of vaccine-preventable diseases. For highly transmissible diseases, such as varicella, this could also limit the herd immunity effect, making it more difficult to effectively control infections at the national level [23]. Moreover, the adoption of different strategies by region has ethical implications, because individuals living in contiguous areas could have a different availability of 
preventive measures. Furthermore, when vaccine offering varies greatly, both health workers and the public could raise doubts on the role of and the need for vaccinations. Information on regional offering of vaccinations should also be regularly collected, since this may evolve rapidly.

For all these reasons, it is now crucial to monitor vaccination coverage rates properly for PCV, MenC and varicella, as these are not now routinely collected at the national level. Analysis of these data, along with disease incidence figures, will help to assess the effectiveness of various strategies implemented at the regional level, in order to harmonise PCV, MenC and varicella recommendations.

* Regional referents for infectious diseases and vaccinations:

R Cassiani (Regione Abruzzo); G Cauzillo, F Locuratolo (Regione Basilicata); G Morosetti (Provincia Autonoma Bolzano); R Curia, A Zaccone (Regione Calabria); R Pizzuti (Regione Campania); AC Finarelli, B Borrini (Regione Emilia-Romagna); G Rocco (Regione Friuli Venezia Giulia); F Curtale (Regione Lazio); R Gasparini (Regione Liguria); M Gramegna, A Pavan, L Macchi (Regione Lombardia); G Grilli (Regione Marche); R Patriarchi, LA D’Alò (Regione Molise); A Barale (Regione Piemonte); R Prato, C Germinario (Regione Puglia); G Rossi (Regione Sardegna); S Ciriminna (Regione Sicilia); E Balocchini (Regione Toscana); V Carraro (Provincia autonoma Trento); A Tosti, M Giaimo (Regione Umbria); L Sudano (Regione Val d'Aosta); A Ferro, S. Milani (Regione Veneto).

\section{References}

1. Pebody RG, Leino T, Nohynek H, Hellenbrand W, Salmaso S, Ruutu P. Pneumococcal vaccination policy in Europe. Euro Surveill 2005;10(9):174-8. Available from: http://www.eurosurveillance.org/em/v10n09/1009-226.asp

2. Lansley $M$, Bedford $H$. Reflections on the meningococcal group $C$ infection immunisation campaign: views from the sharp end. Vaccine. 2003;21(2122):2877-81.

3. Ramet J, Weil-Olivier C, Sedlak W; Confederation of the European Specialists of Paediatrics (CESP)/European Academy of Paediatrics (EAP) CESP/EAP. Is Europe ready to embrace a policy of universal varicella vaccination? Int J Clin Pract. 2005;59(11):1326-33.

4. Cauchemez S, Temime L, Valleron AJ, Varon E, Thomas G, Guillemot D, et al. S. pneumoniae transmission according to inclusion in conjugate vaccines: Bayesian analysis of a longitudinal follow-up in schools. BMC Infect Dis. 2006;6(1):14.

5. Trotter CL, Gay NJ, Edmunds WJ. Dynamic models of meningococcal carriage, disease, and the impact of serogroup C conjugate vaccination. Am J Epidemiol. 2005;162(1):89-100.

6. Pebody RG, Hellenbrand W, Ancona F, Ruutu P. Pneumococcal disease surveillance in Europe. Euro Surveill 2006;11(9):171-8. Available from: http://www.eurosurveillance.org/em/v11n09/1109-226.asp
7. EU-IBIS. European Union Invasive Bacterial Infections Surveillance Network. EU-IBIS 2006 [cited 2006 Apr 27]. Available from: http://www.euibis.org

8. McIntosh ED, Fritzell B, Fletcher MA. Burden of paediatric invasive pneumococcal disease in Europe, 2005. Epidemiol Infect. 2006;1-13.

9. Noah N. Surveillance of bacterial meningitis in Europe 1999/2000. Eurosurveillance Weekly. 2002 Apr 11;4(15) 020411. Available from: http:// www.eurosurveillance.org/ew/2002/020411.asp

10. Gabutti G, Penna C, Rossi M, Salmaso S, Rota MC, Bella A, et al. The seroepidemiology of varicella in Italy. Epidemiol Infect. 2001;126(3):43340.

11. Svahn A, Berggren J, Parke A, Storsaeter J, Thorstensson R, Linde A. Changes in seroprevalence to four herpesviruses over 30 years in Swedish children aged 9-12 years. J Clin Virol. 2006;37(2):118-23.

12. Whitley RJ. Varicella-Zoster virus. In: Mandell GL, Bennet JE, Dolin R, editors. Mandell, Douglas and Bennett's principles and pratices of infectious diseases. 6th edition. Ed. Philadelphia: Elsevier; 2005. p. 1780-5.

13. Lopalco PL. Use of 7-valent pneumococcal conjugate vaccine in EU. Euro Surveill. 2006:11(12):E061207.3. Available from: http://www.eurosurveillance. org/ew/2006/061207.asp\#3

14. Pinot de MA, Nardone A. Varicella zoster virus vaccination policies and surveillance strategies in Europe. Euro Surveill. 2005;10(1):43-5. Available from: http://www.eurosurveillance.org/em/v10n01/1001-222.asp

15. Ministero della Salute. Piano Nazionale Vaccini 2005-2007. December 22, 2005. Available from: http://www.ministerosalute.it/imgs/C_17_normativa_ 526_ulterioriallegati_ulterioreallegato_0_alleg.pdf

16. Sistema Informatizzato Malattie Infettive (SIMI). Istituto Superiore di Sanità. Dati di sorveglianza sulle meningiti. SIMI 2006 [cited 1 april 2006]. Available from: http://www.simi.iss.it/dati.htm

17. D’Ancona F, Salmaso S, Barale A, Boccia D, Lopalco PL, Rizzo C, et al. Incidence of vaccine preventable pneumococcal invasive infections and blood culture practices in Italy. Vaccine. 2005;23(19):2494-500.

18. Jefferson T, Ferroni E, Curtale F, Giorgi RP, Borgia P. Streptococcus pneumoniae in western Europe: serotype distribution and incidence in children less than 2 years old. Lancet Infect Dis. 2006;6(7):405-10.

19. Salmaso S, Tomba GS, Mandolini D, Esposito N. [Assessment of the potential impact in Italy of extensive varicella vaccination programs based on a mathematical model]. Epidemiol Prev. 2003;27(3):154-60. In Italian.

20. Brisson M, Edmunds WJ, Gay NJ. Varicella vaccination: impact of vaccine efficacy on the epidemiology of VZV. J Med Virol. 2003;70 Suppl 1:S31-7.

21. No authors listed. Vaccine-preventable diseases: improving vaccination coverage in children, adolescents, and adults. A report on recommendations from the Task Force on Community Preventive Services. MMWR Recomm Rep. 1999;48(RR-8):1-15.

22. Ciofi Degli Atti ML, Rota MC, Bella A, Salmaso S. Do changes in policy affect vaccine coverage levels? Results of a national study to evaluate childhood vaccination coverage and reasons for missed vaccination in Italy. Vaccine. 2004;22(31-32):4351-7.

23. Ciofi degli Atti ML, Salmaso S, Vellucci L, De Stefano D. New measles epidemic in southern Italy: 1217 cases reported to sentinel surveillance, January-May 2003. Eurosurveillance Weekly. 2003;7(27) 030703. Available from: http:// www.eurosurveillance.org/ew/2003/030703.asp\#1

Citation: D’Ancona F, Alfonsi V, Caporali M, Ranghiasci A, Ciofi Degli Atti M, Euro Surveill 2007;12(2)[Epub ahead of print]. Available online: http://www. Euro Surveill 2007;12(2) [ Epub ahead of prot
eurosurveillance.org/em/v12n02/1202-225.asp 